\title{
MULTIVARIATE ASSESSMENT OF THE PHENETIC AFFINITIES OF AUSTRALASIAN OYSTERCATCHERS (AVES: CHARADRIIFORMES)
}

\author{
by \\ ALLAN J. BAKER \\ Department of Ornithology, Royal Ontario Museum, and Department of Zoology, \\ University of Toronto, Toronto, Ontario, Canada
}

\begin{abstract}
Phenetic affinities of Australasian oystercatchers were elucidated by multivariate statistical analysis of seven morphometric characters taken from museum skins. Nineteen operational taxonomic units (OTUs), representing all the currently recognized species and most of the subordinate taxa, were used to calibrate morphological variation in Australasian Haematopus against the range displayed by the Haematopodidae. The rather homogeneous nature of variation among OTUs was not well suited for analysis by hierarchical clustering methods, but a non-hierarchical ordination method utilizing both principal components and nonmetric scaling produced excellent summaries of the similarity matrices.

The South Island Pied Oystercatcher ( $H . o$. finschi) of New Zealand clustered tightly with the Eurasian $H$. ostralegus and thus seems to be of Palaearctic origin. All the remaining Australasian taxa grouped in another cluster with the New World forms, and it appears likely that the Australian Pied Oystercatcher will have to be split from the ostralegus group as a separate species. Comments on the taxonomy and zoogeography of the family are postponed until a current study of a much larger data set is completed.

\footnotetext{
"It cannot be but mischievous to any study to have divers systems of nomenclature simultaneously co-existent in the same dominion." Milligan (1911).
}

\section{INTRODUCTION}

Australasian oystercatchers are widely distributed around the sea shores of New Zealand, Australia, most islands in Torres Straits, Misima, Kai and Aru Islands, and the southern coast of New Guinea (Condon, 1975). The affinities and hence the number of taxa that should be recognized from this region have been subject to lively debate in the past, and remain largely unresolved today.

I have outlined previously the chaotic nomenclatural history of the New Zealand taxa, and have suggested that this instability was due primarily to an essentially typological assessment of varia- tion in morphological characters (Baker, 1975). The Australian taxa have suffered similar treatment, as illustrated below. The first oystercatcher to receive formal recognition was a pied bird, described by Vieillot (1817) as Haematopus longirostris. Three further pied birds from northwestern Australia, New South Wales and Queensland were described respectively as $H$. picatus King, 1826, $H$. australianus Gould, 1838 and $H$. longirostris mattingleyi Mathews, 1912. Mathews (1912) synonymized $H$. australianus with the nominate $H$. l. longirostris, and restricted picatus as a subspecies of $H$. longirostris. The following year he submerged these taxa under $H$. ostralegus longirostris Vieillot, ostensibly because of the paucity of material then available by which good subspecies could be recognized (Mathews, 1913). All Australian pied birds were subsequently lumped under $H$. ostralegus Linnaeus, 1758 , by Mathews $\&$ Iredale (1921), and no subordinate taxa were designated. Mathews (1927) assigned longirostris and picatus as subspecies of $H$. ostralegus, but Peters (1934) considered only $H$. o. longirostris as valid. Oliver (1955) concluded that specimens from New South Wales, northern New Zealand and the Chatham Islands were all referable to one species, $H$. longirostris. Condon (1975) relegated longirostris to a subspecies of $H$. ostralegus, but noted that "the taxonomy is very confused and some authors are inclined to follow Oliver".

Similar taxonomic confusion is apparent for the melanistic oystercatchers of Australia. The original description of the Sooty Oystercatcher was given by Gould (1845) as Haematopus fuliginosus. 
Castelnau \& Ramsay (1877) erected a new species, H. opbthalmicus (lapsus calumni), for a melanistic specimen with a large fleshy patch around the eye from Bountiful Island in the Gulf of Carpentaria. In 1912 Mathews referred both fuliginosus and opbthalmicus to subspecies of the New Zealand oystercatcher $H$. unicolor Forster, 1844 and erected a new subspecies $H$. $u$. bernieri for a specimen from Bernier Island in Western Australia. On the basis of supposed priority he synonymized unicolor with niger in 1913, but retained the above subspecies. Mathews \& Iredale (1921) reversed this decision and submerged all taxa under $H$. unicolor. In 1927 Mathews reinstated fuliginosus, ophthalmicus and bernieri as subspecies of $H$. unicolor, but Peters (1934) rejected unicolor as a species epithet and recognized only $H$. $f$. fuliginosus and $H$. $f$. ophthalmicus from Australia. These latter taxa have endured since and are used by Condon (1975).

The cluttering of the literature. with numerous nomenclatural changes is perhaps understandable in the context of the nature and relative recency of ornithological discovery in Australasia. However, if progress is to be made beyond the point where taxonomic decisions reflect little more than the personal preferences of their proponents, it is clear that a substantive study of the systematic relationships of the taxa will have to be made. The taxonomic instability outlined above stems principally from an inadequate assessment of the affinities of allopatric taxa, especially those from the Old and New Worlds. This paper presents a multivariate analysis of the phenetic affinities of Australasian oystercatchers, based on external morphometric skin characters traditionally used by avian systematists.

\section{MATERIALS AND METHODS}

\section{Selection of taxa for comparative study}

Because the phenetic affinities of Australasian Haematopus need to be cast in the broader perspective of the range of morphological variation in the Haematopodidae, the selection of taxa for comparative study is most important. Where multivariate statistical methods are used, this sampling factor becomes critical because the configuration of the multidimensional space defined by the characters and/or the taxa is dependent on the range of variation spanned. If the placement of taxa in such a space is to be a reliable and repeatable representation of their phenetic affinities, then it follows that as many taxa as possible should be treated in the analysis. I have used all the data available to me, and only $H$. palliatus galapagensis, $H$. p. pitanay and $H$. p. durnfordi are not represented. As some of the taxa used in this study are actually represented by individuals, I have followed Sneath \& Sokal (1973) hereafter in employing the terminology operational taxonomic units (OTUs).

The OTUs used in this study, the number of species in each and their geographic range in the breeding season are given in table I. The nomenclature used is that of current checklists and connotes no taxonomic decisions on my part. For heuristic purposes, and to provide a yardstick by which distances among OTUs can be judged, I have included hybridizing forms as separate OTUs. For example, the melanistic $H$. u. unicolor and the pied $H$. u. reischeki hybridize so extensively in northern New Zealand that they might well be lumped together in a single taxon if the extent of gene exchange is the final arbiter. Conversely, although $H$. bachmani hybridizes with $H$. palliatus in lower California, the hybrid population (here referred to as $H$. p. frazeri) is relatively restricted in distribution and thus the integrity of the gene pools of the parental species is essentially maintained.

\section{Selection of characters}

Although numerical taxonomists such as Sneath \& Sokal (1973) advocate the use of large suites of characters (commonly 60 or more) so that similarity coefficients will have reasonable confidence levels, in this study I have used only the seven external morphological characters traditionally used by avian systematists in assessing the affinities of closely related taxa. While I acknowledge that the use of a small number of characters may decrease the reliability of the statistical results, my intention is not to construct a numerical taxonomy as such, but rather to obtain a more complete evaluation of the morphometric information contained in a traditional character suite. The characters used 
TABLe I

OTUs used in this study, their sample sizes and geographic ranges.

\begin{tabular}{|c|c|c|c|c|c|}
\hline \multicolumn{2}{|c|}{ OTU } & \multirow[b]{2}{*}{ Abbreviation } & \multicolumn{2}{|c|}{$n$} & \multirow[t]{2}{*}{ Geographic range in the breeding season ${ }^{1}$ ) } \\
\hline no. & OTU designation & & 99 & $\bar{\delta} \hat{o}$ & \\
\hline 1 & Haematopus ostralegus malacophaga & H.o.mala. & 18 & 17 & Iceland and Faeroe Islands \\
\hline 2 & H. o. occidentalis & H.o.occi. & 22 & 21 & British Isles \\
\hline 3 & H. o. ostralegus & H.o.ostr. & 40 & 37 & $\begin{array}{l}\text { Europe east to Arkhangelsk and south to Spain } \\
\text { and Baltic Sea; coasts of Asia Minor, Mace- } \\
\text { donia, the Black and Caspian Seas }\end{array}$ \\
\hline 4 & H. o. longipes & H.o long. & 10 & 1 & $\begin{array}{l}\text { Inland southern and eastern Russia and western } \\
\text { Siberia }\end{array}$ \\
\hline 5 & H. o. finschi & H.o.fins. & 18 & 20 & South Island of New Zealand \\
\hline 6 & H. o. osculans & H.o.oscu. & 5 & 11 & $\begin{array}{l}\text { Coasts of northeastern Russia from eastern } \\
\text { Siberia to northern China }\end{array}$ \\
\hline 7 & H. o. longirostris & H.o.rost. & 41 & 45 & $\begin{array}{l}\text { New Guinea south through Australia to Tas- } \\
\text { mania }\end{array}$ \\
\hline 8 & H. chatbamensis & H.chat. & 14 & 14 & Chatham Islands \\
\hline 9 & H. fuliginosus fuliginosus & H.f.fuli. & 21 & 28 & Coasts of Australia except ophthalmicus range \\
\hline 10 & H. f. opbtbalmicus & H.f.opht. & 3 & 4 & $\begin{array}{l}\text { Northern Australia coast from Cape York } \\
\text { Peninsula west to Kimberleys }\end{array}$ \\
\hline 11 & H. unicolor unicolor & H.u.unic. & 20 & 21 & New Zealand \\
\hline 12 & H. u. reiscbeki & H.u.reis. & 17 & 17 & North Island of New Zealand \\
\hline 13 & H. moquini moquini & H.m.moqu. & 8 & 8 & $\begin{array}{l}\text { Coasts of South Africa from Natal to South- } \\
\text { west Africa }\end{array}$ \\
\hline 14 & H. m. meadewaldoi & H.m.mead. & 1 & 1 & Eastern Canary Islands (probably extinct) \\
\hline 15 & H. palliatus palliatus & H.p.pall. & 4 & 11 & $\begin{array}{l}\text { Atlantic and Pacific coasts of North and } \\
\text { Central South America }\end{array}$ \\
\hline 16 & H. p. frazeri & H.p.fraz. & 11 & 18 & Lower California south to Jalisco \\
\hline 17 & $H$. ater & H.ater & 14 & 29 & $\begin{array}{l}\text { Coasts of South America from about } 10^{\circ} \mathrm{S} \text { on } \\
\text { the west to about } 43^{\circ} \mathrm{S} \text { on the east; Falkland } \\
\text { Islands }\end{array}$ \\
\hline 18 & H. bacbmani & H.bach. & 17 & 15 & $\begin{array}{l}\text { Aleutian Islands through Alaska west to Lower } \\
\text { California }\end{array}$ \\
\hline \multirow[t]{2}{*}{19} & H. leucopodus & H leuc. & 1 & 3 & $\begin{array}{l}\text { Southern South Africa from Chiloe Island } \\
\text {-round to Chubut: Falkland Islands }\end{array}$ \\
\hline & & Totals & 285 & 321 & \\
\hline
\end{tabular}

1) These ranges are mapped more exactly in Baker (1973).

and their methods of measurement are outlined below: (1) Bill length - measured along the dorsal surface of the culmen from the tip to the junction of the feathers. (2) Bill depth - measured from the junction of the feathers with the culmen on the upper mandible to the exposed portions of the mandibular rami on the lower mandible. (3) Bill width - measured at the widest point of the bill beneath the dorsal feather margin on the upper mandible. (4) Tarsus length - measured diagonally from the posterior aspect of the joint between the tibiotarsus and the tarsometatarsus, to the anterior aspect of the joint between the tarsometatarsus and the middle toe. (5) Middle toe length - measured dorsally from the joint with the tarsometatarsus to the base of the claw. (6) Tail length - measured from the point of emergence of the two central rectrices to the tip of the longest rectrix. (7) Wing length measured as the chord of the flattened wing, from the carpal flexure to the tip of the outermost primary feather. The first five measurements were taken with dial calipers to the nearest $0.1 \mathrm{~mm}$, and the remaining two were measured with a steel rule accurate to $1 \mathrm{~mm}$.

\section{Statistical methods}

As oystercatchers are markedly sexually dimorphic in size (Baker, 1975), character variation in males and females was analyzed separately beyond. The raw data matrix for each sex was too large to handle practically at the level of individuals, so 
means were calculated for each OTU (except for those where $n=1$ ) and the dimensions of the data matrix were correspondingly reduced to $19 \times 7$ (number of OTUs $\times$ number of characters).

Prior to the calculation of similarity coefficients, the characters were standardized across OTUs so that they had a mean of zero and a standard deviation of one, and thus each character theoretically can contribute equal information in the ensuing analyses. Average taxonomic distances $(d)$ and product-moment correlation coefficients $(r)$ were then computed among OTUs, and separate cluster analyses were performed using the unweighted pair-group method on arithmetic averages (UPGMA - Sneath \& Sokal, 1973). UPGMA clustering was initially used because it usually gives the least distortion when represented by a two-dimensional phenogram (Sokal \& Rohlf, 1962; Farris, 1969; Rohlf, 1970). Cophenetic correlations between the phenograms and the original distance and correlation matrices were calculated to determine how accurately the phenograms summarized the similarity coefficients.

The results of hierarchical clustering were tested against a non-hierarchical ordination technique combining both principal component analysis (PCA) and nonmetric multidimensional scaling analysis (MDSCALE). This dual approach utilizes the results of PCA as an initial input configuration for the MDSCALE routine.

The value of principal component transformation of morphometric data derives from the assessment of simultaneous variation in all characters over all OTUs, and the consequent reduction of a large data matrix to a much smaller set of orthogonal (and thus uncorrelated) principal components. The MDSCALE technique, on the other hand, represents $t$ OTUs geometrically by $t$ points in a reduced space of $k$ dimensions (where $k \ll t$; $k$ typically $=2$ or 3 ) such that the interpoint distances have a monotone relationship with the distances among the OTUs in the original dissimilarity matrix. MDSCALE differs from PCA in requiring only that the monotone relationship is preserved in the reduced space, rather than explaining a maximum percentage of the variation. Results of the two techniques are in practice quite similar, but MDSCALE more faithfully preserves the distances between the OTUs in the reduced space (Rohlf, 1970). The goodness of fit of the MDSCALE solution to the distance matrix was assessed by computing stress values (see Kruskal, 1964) and the matrix correlation $r_{d d}{ }^{*}$ (Rohlf, 1972).

In this study the OTUs were projected into a three-dimensional space, and a minimum spanning tree (MST) computed from the original distance matrix was superimposed to provide additional insights on the phenetic relationships of the OTUs. Distinctive clusters of OTUs in the three-dimensional MDSCALE ordinations were isolated using subsets analysis. This technique finds all subsets of OTUs satisfying the condition that the greatest dissimilarity between OTUs in the subset is less than the least dissimilarity between any OTU in the subset and any OTU not in the subset. Only the complete set of OTUs and single OTUs are not permitted as subsets.

\section{RESULTS}

\section{Cluster analysis}

The morphometric relationships of the 19 OTUs, as elucidated by UPGMA cluster analyses of the $r$ and $d$ matrices, are shown for adult females and males in fig. 1. Results for both sexes are quite disparate for the two coefficients of similarity.

For females, three clusters are produced from correlation coefficients and two from average taxonomic distances. Moreover, the composition of clusters changes somewhat for the two coefficients. While cluster analysis of the $r$ matrix (fig. 1a) faithfully preserves the known close phenetic relationships between the hybridizing forms of northern New Zealand (H. u. unicolor and $H . u$. reischeki) and lower California (H. p. palliatus and $H . p$. frazeri), it has the disruptive effect of separating the OTUs representing the western European subspecies of $H$. ostralegus into different clusters. More specifically, it breaks off $H . O$. occidentalis and $H$. o. malacophaga (British, Icelandic and Faeroe birds) from the cluster including the nominate $H$. o. ostralegus (the remaining western European birds). The central European and Eurasian subspecies (H. o. longipes and H.o. osculans respectively) group with $H$. o. ostralegus, 

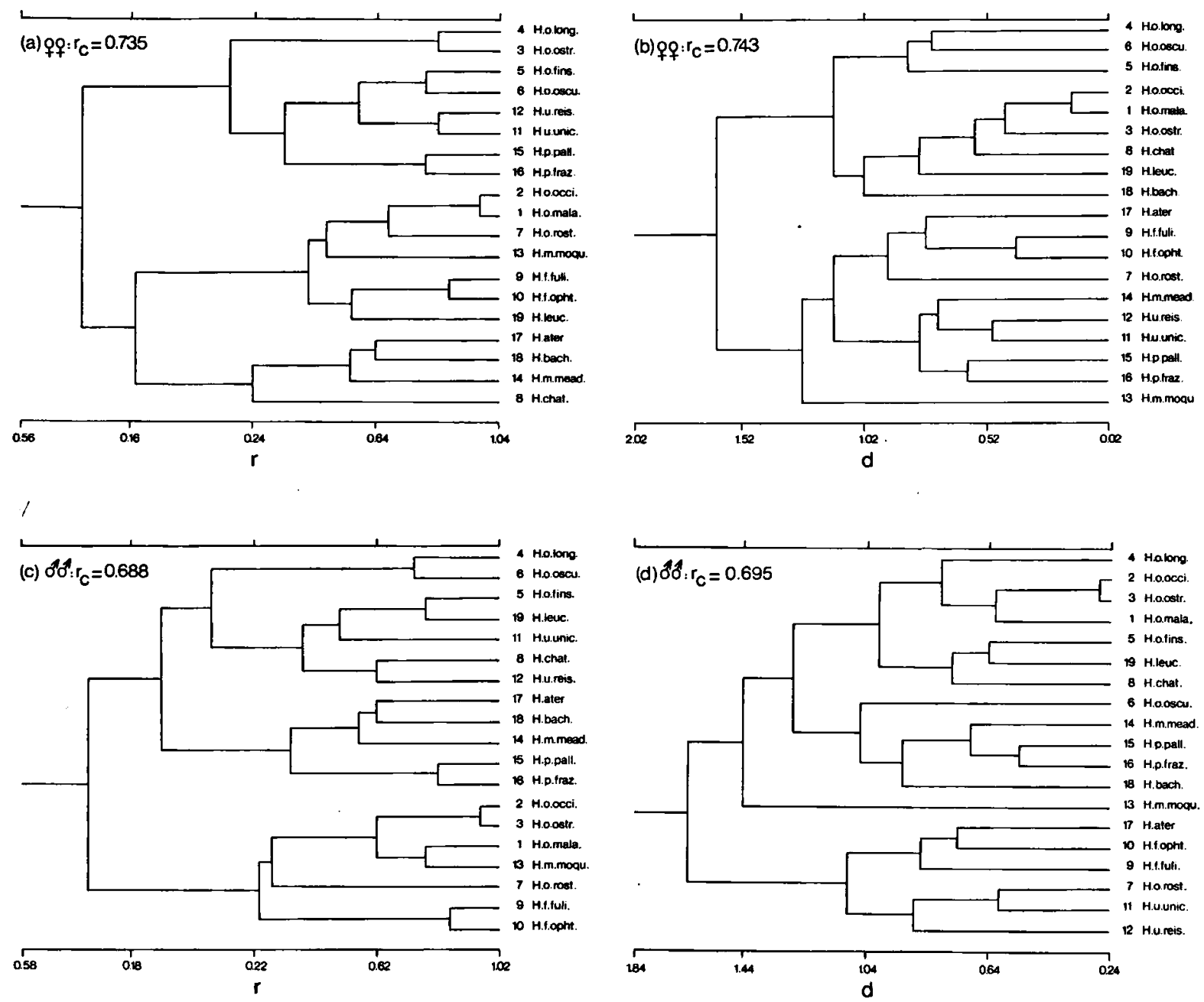

Fig. 1. Phenograms from UPGlMA cluster analysis of similarity matrices: (a) correlation phenogram for females, (b) distance phenogram for females, (c) correlation phenogram for males, (d) distance phenogram for males. OTUs are identified as in table I and cophenetic correlations are denoted by $\boldsymbol{r}_{\boldsymbol{c}}$.

and with $H . O$. finschi of New Zealand. The Australian Pied Oystercatcher (H. o. longirostris) clusters with western European $H$. ostralegus and the melanistic $H$. m. moquini of South Africa. Both Australian subspecies of the Sooty Oystercatcher $(H$. fuliginosus) group together. The Chatham Islands Oystercatcher ( $H$. chathamensis) appears as an aberrant form distantly related to the Canary Islands $H . m$. meadewaldoi.

Results of the cluster analysis of the matrix of average taxonomic distances (fig. 1b) are intuitively more appealing (though note the comments of Rohlf \& Sokal (1965) to the contrary regarding size-ordered classification from $d$ matrices), not only because they are largely consistent with taxonomies adopted by recent checklists (e.g. Kinsky, 1970; Condon, 1975), but also because they are explicable in terms of zoogeographic and evolutionary processes. All the subspecies of $H$. ostralegus except $H$. o. longirostris fall within a major cluster, and the New Zealand $H$. o. finschi shows closest phenetic affinities with the Eurasian $H . O$. longipes and $H$. o. osculans. $H$. chathamensis of the Chatham Islands clusters with western European subspecies of $H$. ostralegus and the New World $H$. leucopodus and $H$. bachmani. Both Australian subspecies of $H$. fuliginosus group together and link with the South American Black 
Oystercatcher $(H$. ater $)$ and the Australian Pied Oystercatcher ( $H . o$. longirostris). The hybridizing forms of both $H$. unicolor and $H$. palliatus form compact groups and together form a broader cluster, with the South African $H . m$. moquini and the Canary Islands $H . m$. meadewaldo $i$ as more distant outliers.

Neither of the phenograms are particularly good in summarizing the information in the similarity matrices. Cophenetic correlations are only 0.735 for the correlation coefficient phenogram and 0.743 for the distance phenogram. Cluster analysis of OTUs of males, as with females, produces three clusters with correlation coefficients and two with average taxonomic distances. The membership of clusters differs between the sexes, but the overall patterns of groupings of OTUs are broadly similar. Cluster analysis of the $r$ matrix again partitions the subspecies of $H$. ostralegus into different clusters, but more disturbingly $H$. chathamensis is inserted between the hybridizing forms of $H$. unicolor (fig. 1c). The integrity of the $H$. palliatus complex is maintained, however, and the two subspecies of $H$. fuliginosus group together. Western European subspecies of $H$. ostralegus appear to be phenetically closest to the South African $H . m$. moquini and the Australian $H$. o. longirostris.

The results of cluster analysis on the $d$ matrix of males (fig. 1d) are again intuitively much more satisfactory than those from the $r$ matrix. All the Eurasian subspecies of $H$. ostralegus except $H . O$. osculans appear in the same cluster, along with the ostralegus-like $H$. leucopodus of South America and H. chatbamensis of the Chatham Islands. H.o. osculans is a distant outlier in a cluster including the hybridizing forms of $H$. palliatus from lower California and the Canary Island Oystercatcher (H. m. meadewaldoi). The OTUs representing $H$. unicolor and $H$. fuliginosus are clustered together with $H$. ater of South America.

Both phenograms of males provide relatively poor fits with the similarity values in the $r$ and $d$ matrices. The cophenetic correlations are only 0.688 for the correlation coefficients and 0.695 for the average taxonomic distances. This disappointing result reflects the weakly hierarchical nature of the similarity matrices, which in turn derives from the relatively constrained and homo- geneous range of phenetic variation found in the Haematopodidae.

\section{Principal components analysis}

Because the PCA projections of the OTUs are quite similar to those of MDSCALE in this study, they will not be presented here. However, it is useful to inspect the pattern of loadings of the characters on the first three principal components, as they aid considerably in interpreting the axes of the MDSCALE ordination. For females, $91.7 \%$ of the character variance is accounted for on the first three principal components; $59.8 \%$ on component I, $20.2 \%$ on II and $11.7 \%$ on III. For males, $86.9 \%$ of the character variance is accounted for by the first three principal components; $54.4 \%$ on component I, $21.2 \%$ on II and $11.3 \%$ on III.

The loading patterns are similar for the sexes (table II). Component I has high positive loadings for all characters except bill length, and therefore serves to differentiate the OTUs largely on the basis of size. Component II is effective in distinguishing OTUs chiefly on an inverse relationship between bill length (and tarsus length to a lesser degree) and tail length. Middle toe length and bill width load positively, and wing and tail lengths load negatively on component III of females, and the reverse is apparent for males. Hence component III seems to involve similar contrasts in these characters across OTUs.

\section{TABLE II}

Loading of characters on the first three principal components based on a matrix of correlations among morphological characters.

\begin{tabular}{llcrr}
\hline Character & Sex & $\begin{array}{c}\text { Com- } \\
\text { ponent I }\end{array}$ & $\begin{array}{c}\text { Com- } \\
\text { ponent II }\end{array}$ & $\begin{array}{c}\text { Com- } \\
\text { ponent III }\end{array}$ \\
\hline Bill length & Male & 0.163 & -0.880 & 0.405 \\
& Female & 0.236 & -0.919 & -0.261 \\
Bill depth & Male & 0.849 & -0.248 & -0.031 \\
& Female & 0.894 & -0.142 & -0.103 \\
Bill width & Male & 0.837 & -0.220 & -0.381 \\
& Female & 0.901 & -0.088 & 0.320 \\
Tarsus length & Male & 0.804 & 0.304 & 0.132 \\
& Female & 0.808 & -0.411 & 0.056 \\
Middle toe length & Male & 0.797 & 0.140 & -0.433 \\
& Female & 0.763 & 0.184 & 0.575 \\
Wing length & Male & 0.821 & 0.350 & 0.296 \\
& Female & 0.863 & 0.277 & -0.376 \\
Tail length & Male & 0.634 & 0.605 & 0.433 \\
& Female & 0.733 & 0.512 & 0.402 \\
\hline
\end{tabular}


Nonmetric multidimensional scaling and subsets analysis

The three-dimensional MDSCALE ordinations of females and males differ somewhat in the placement of particular OTUs, but the general pattern of phenetic relationships expressed therein is similar (fig. 2). In both ordinations the Eurasian subspecies of $H$. ostralegus group together and have clear phenetic affinities with $H$. o. finschi of New Zealand, $H$. leucopodus of South America and H. bachmani of western North America. All the remaining Australasian taxa group together within another major grouping containing all the New World OTUs. The African $H$. moquini is phenetically intermediate, appearing nearer the New World group of females (fig. 2a) and the Old World group of males (fig. 2b).

Distinctive clusters of OTUs within the two major groups are indicated by the subsets procedure. For females, the western European subspecies $H . o$ ooccidentalis and $H . o$. malacophaga are very similar phenetically, as are the Eurasian subspecies $H . o$. longipes and $H . o$. osculans. As might be expected, for both sexes the New World and New Zealand hybridizing forms fall into specific subsets, as do the subspecies of the Australian $H$. fuliginosus. A slightly different group of subsets emerges for Old World males; H. o. occidentalis has closest phenetic affinity with $H . o$. ostralegus, and $H$. o. finschi of New Zealand appears in the same subset as $H$. leucopodus of South America.

The low stress values $(s)$ and the high matrix correlations $\left(r_{d d^{*}}\right)$ indicate that the ordinations provide an excellent fit to the phenetic relationships represented in the matrix of average taxonomic distances. Given the small sample sizes on which some OTUs are based, and the small number of characters used, the degree of concordance of the ordination patterns of males and females attests to the robustness and utility of the joint PCA/ MDSCALE approach.

\section{DISCUSSION}

Taxonomists have long been impressed by the distinctive but uniform morphology of oyster- catchers, and have accordingly classified them in a single monogeneric family. Consensus has ended at the generic level, however, because of the seemingly intractable nature of morphometric variation of allopatric forms, the lack of a global view in assessing affinities, and the confounding influence of melanism which has probably arisen independently in several geographically widespread taxa (e.g. H. unicolor in New Zealand, $H$. fuliginosus in Australia, H. moquini in Africa, $H$. ater in South America and H. bachmani in North America).

Taxonomic problems within the Haematopodidae are thus similar to those encountered within homogeneous assemblages such as species-complexes, and their successful resolution often depends on a careful synthesis of relevant data from morphology, ecology, ethology, physiology etc. (Mayr, 1969). This approach has been fruitful for the New Zealand taxa (Baker, 1974), but reliable data from such diverse disciplines as these are as yet unavailable even for the Australasian taxa.

Yet, there is still much valuable taxonomic information to be gleaned from morphological data sets. The use of non-hierarchical ordination methods seems particularly appropriate for analyzing phenetic relationships of homogenous taxa as the methods do not force them into a rigid and possibly artificial hierarchy. In this study multivariate analysis of an admittedly small set of characters long used by avian systematists has given new insights into the nature of morphological variation in oystercatchers. Of particular importance in this respect is the finding that two principal groups of OTUs can be defined, one an Old World group with a solid nucleus of Eurasian $H$. ostralegus and the other a New World group, which also includes all the Australasian OTUs except $H$. o. finschi of New Zealand. This latter taxon seems better considered as a Palaearctic element in the New Zealand fauna (following a secondary invasion) rather than a Holarctic element as suggested by Fleming (1962). Conversely, the Australian $H$. o. longirostris appears to be phenetically similar to the New World forms, and should probably be given full species rank. However, zoogeographic and taxonomic speculation 
(a)

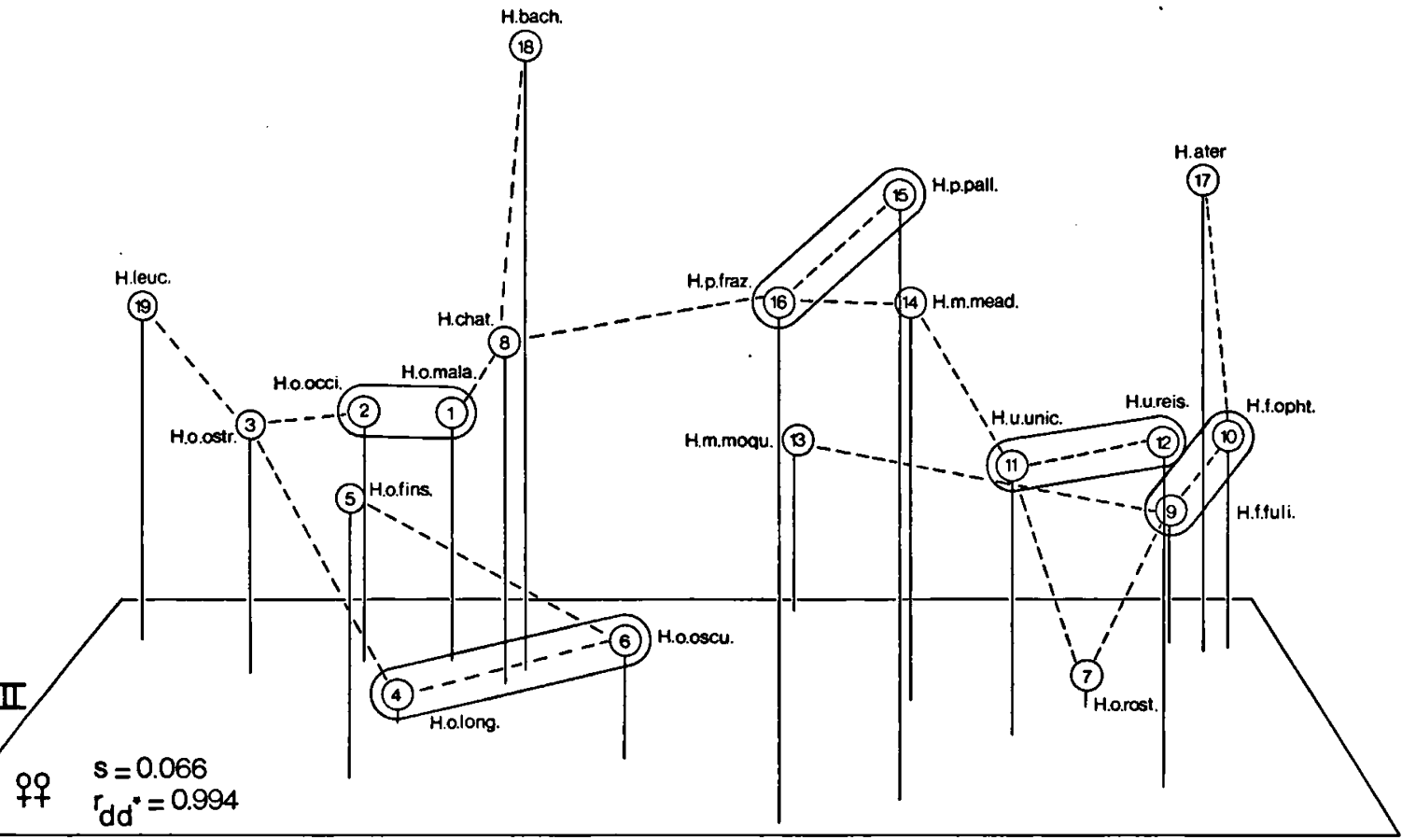

I

(b)

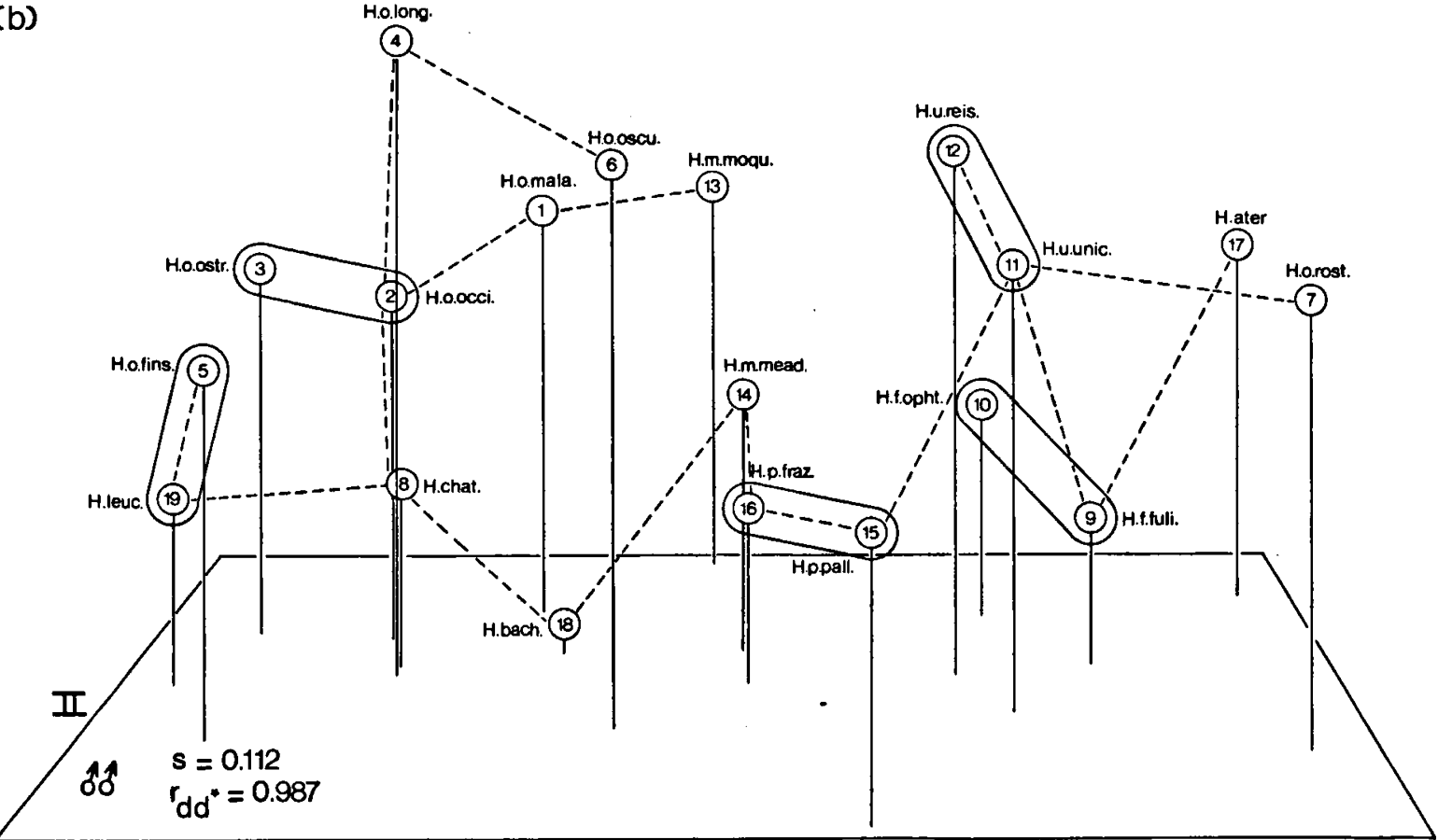

I

Fig. 2. Three-dimensional ordinations using the PCA/MDSCALE method: (a) females, (b) males. Dimension III is represented by the height of the projections. OTUs are identified as in table I, stress is denoted by $s$ and the matrix correlation by $r_{d d^{*}}$. The MST is indicated by the dashed lines, and joins phenetically similar OTUs together. Distinctive clusters of OTUs defined by the subsets procedure are enclosed by solid lines. 
based on the present data set is obviously premature, and must await the results of a study of a much larger set of skeletal and biochemical characters, currently in progress.

\section{ACKNOWLEDGEMENTS}

For permission to examine collections in their care I am grateful to the following colleagues: Mr. H. J. de S. Disney, Australian Museum, Mr. H. T. Condon, South Australian Museum, Dr. N. K. Johnson, Museum of Vertebrate Zoology, University of California, Berkeley, Mr. F. C. Kinsky, National Museum of New Zealand, Mr. A. R. McEvey, National Museum of Victoria, Dr. G. F. Mees, Rijksmuseum van Natuurlijke Historie, Leiden, Dr. F. Salomonsen, Universitets Zoologiske Museum, Copenhagen, Mr. R. Scarlett, Canterbury Museum, Dr. L. L. Shortt, American Museum of Natural History, Dr. D. W. Snow, British Museum (Natural History), Dr. P. J. Stanbury, Macleay Museum, University of Sydney, Dr. R. W. Storer, Museum of Zoology, University of Michigan, Dr. G. F. Storr, Western Australian Museum, Mrs. A. M. Sudilovskaja, Zoological Museum, University of Moscow, Mr. E. G. Turbott, Auckland Institute and Museum, Mr. D. P. Vernon, Queensland Museum and Dr. J. Wattel, Zoological Museum, University of Amsterdam. The figures were drafted skilfully by Maria Tran Thi Vinh-Hao, and the manuscript was typed by Greta Vooren. I would also like to thank Drs. F. Peeters-Pieters and Mr. J. Paul for assistance in locating some of the earlier literature. Computations were carried out at the University of Toronto Computer Centre using an IBM 370/165 computer. All multivariate analyses were run using the NT-SYS system of programs developed by F. J. Rohlf, J. Kishpaugh and D. Kirk at the State University of New York, Stony Brook. This study was made possible by financial support from the Royal Ontario Museum. The present paper was prepared during a visit with Dr. Ian R. Ball, and I especially want to thank him and other staff members of the Zoological Museum, University of Amsterdam, for providing facilities and support.

\section{REFERENCES}

Baker, A. J., 1973. Distribution and numbers of New Zealand oystercatchers. Notornis, 20 (2): 128-144.

- 1974. Ecological and behavioural evidence for the systematic status of New Zealand oystercatchers (Charadriiformes: Haematopodidae). Life Sci. Contr., R. Ont. Mus., 96: 1-34.

-, 1975. Morphological variation, hybridization and systematics of New Zealand oystercatchers (Charadriiformes: Haematopodidae). J. Zool., Lond., 161: 357-390.

Castelnau, le Comte de \& E. P. Ramsay, 1877. Notes of a collection of birds from the Norman River, Gulf of Carpentaria, with descriptions of some new species. Proc. Linn. Soc. N.S.W., 1 (4): 379-386.

Condon, H. T., 1975. Checklist of the birds of Australia, 1. Non-passerines: 1.311 (Royal Australian Ornithologists' Union, Melbourne).

FARRIS, J. S., 1969. On the cophenetic correlation coefficient. Syst. Zool., 18 (3): 279-285.

Fleming, C. A., 1962. New Zealand biogeography; a paleontologist's approach. Tuatara, 10 (2): 53-108.

Gould, J., 1845. Haematopus fuliginosus, Gould. Sooty Oyster-catcher. In: J. GouLd, Birds of Australia, 6 [(18)]: [8], pl. VIII (J. Gould, London).

KINSKY, F. C., 1970. Annotated checklist of the birds of New Zealand including the birds of the Ross dependency: 1-96 (Reed, Wellington).

KRUSKAL, J. B., 1964. Multidimensional scaling by optimizing goodness of fit to a nonmetric hypothesis. Psychometrika, 29 (1): 1-27.

Mathews, G. M., 1912. A reference list to the birds of Australia. Novit. Zool., 18 (3): 171-455.

, 1913. A list of the birds of Australia: 1-453 (Witherby \& Co., London).

_ 1927. Systema avium Australasianarum. A systematic list of the birds of the Australasian region: 1-1027 (British Ornithologists' Union, London).

Mathews, G. M. \& T. Iredale, 1921. A manual of the birds of Australia, 1: 1-279 (Witherby \& Co., London).

MAYR, E., 1969. Principles of systematic zoology: $1-428$ (McGraw-Hill, New York).

Oliver, W. R. B., 1955. New Zealand birds (2nd ed., revised): 1-661 (Reed, Wellington).

Peters, J. L., 1934. Check-list of birds of the world, 2: 1-401 (Harvard University Press, Cambridge, Mass.).

RoHLF, F. J., 1970. Adaptive hierarchical clustering schemes. Syst. Zool., 19 (1): 58-82.

- , 1972. An empirical comparison of three ordination techniques in numerical taxonomy. Syst. Zool., 21 (3): 271-280.

Rohlf, F. J. \& R. R. Sokal, 1965. Coefficients of correlation and distance in numerical taxonomy. Univ. Kansas Sci. Bull., 45 (1) : 3-27.

SNeATH, P. H. A. \& R. R. Sokal, 1973. Numerical taxonomy: 1-573 (Freeman, San Francisco).

SoKAL, R. R. \& F. J. RohlF, 1962. The comparison of dendrograms by objective methods. Taxon, 11 (1): 33-44.

Vieillot, L. J. P., 1817. L'Huitrier à long bec, Haematopus longirostris, Vieill. In: Nouveau dictionnaire d'histoire naturelle, appliquée aux arts, à l'agriculture, à l'économie rurale et domestique, à la médecine, etc. par une société de naturalistes et d'agriculteurs [éd. 2], 15: 410 (Déterville, Paris). 